\title{
Myocardial Revascularization Surgery with Regional Anesthesia Without an Endotracheal Tube in Conscious Patients
}

\author{
Gladyston Luiz Lima Souto, Celme da Silva Caetano Júnior, Ary Getúlio de Paula Filho, \\ Marco Antonio Teixeira, Márcio Roberto Moraes de Carvalho, Antonio Carlos Botelho da Silva
}

Itaperuna, RJ - Brazil

\begin{abstract}
Objective - To report initial experience with myocardial revascularization surgery (MRS) performed on patients who were totally awake and without an endotracheal tube.
\end{abstract}

Methods - Between January 1994 and May 2001, 272 patients underwent MRS without extracorporeal circulation. In 24, the operations were performed without the use of an endotracheal tube and with the patients totally awake and breathing normally. The age ranged from 51-75 years with the predominant male sex. Epidural thoracic administratios of the anesthesia was performed. Surgery was performed through a habitual anterolateral thoracotomy. During the entire procedure, the left lung remained partially collapsed.

Results - The 24 patients progressed well through the surgery. Pneumothorax time ranged from 70-190 minutes. No electrocardiographic, echocardiographic, or enzymatic alterations occurred that characterized preand postoperative infarcts. Twenty-three patients were stable enough to be released after 24 hours.

Conclusion - This technique could be performed on an large number of selected patients. However, more experience is necessary.

Key words: coronary artery leypass graft, epidural thoracic anesthesia.
Hospital São José do Avaí - Itaperuna, RJ

Mailing address: Gladyston Luiz Lima Souto - Hospital São José do Avaí - Rua Lenira Tinoco Calheiros, 242 - 28300-000 - Itaperuna, RJ - E-mail: glsouto@ cardiol.br
The development of coronary artery bypass graft surgery $(\mathrm{CABG})$ has progressed throughout practically all of the twentieth century, with intervals of inactivity and progress. Alex Carrel ${ }^{1}$, in 1910, reported the first experimental aorta-coronary graft performed, using a segment of the carotid artery to connect the coronary artery to the descending aorta. At that time, the pneumothorax created was a serious problem. Murray et $\mathrm{al}^{2}$ developed a large number of anastomoses between the coronary arteries and the systemic arteries, including the internal thoracic arteries.

The experimental work of suturing with instruments began in Russia. Kahn et al ${ }^{3}$ performed coronary anastomoses in calves with a Russian-American stapler and had promising results. Kolosov et al ${ }^{4-6}$ in St. Petersburg was a pioneer in clinical work with left internal thoracic artery (LITA) anastomosis with the left anterior descending artery without cardiopulmonary bypass (CPB) similar to other types of grafts. Garrett et $\mathrm{al}^{7}$ described a case of an aorta-coronary bypass with a saphenous vein graft, with the heart beating, with the graft patent after 7 years. This technique did not become popular and was not discussed.

In recent decades, the study of multiple organ dysfunction caused by $\mathrm{CPB}^{8-12}$, the necessity of a longer hospital stay, the short- and long-term results, and the higher cost of this procedure have caused the scientific focus to change. The current trend is toward less aggressive surgery and the development of minimally invasive direct coronary artery bypass (MIDCAB) without CPB.

Reports of this new approach have been widely published including those by Trapp and Bisarya ${ }^{13}$ in Canada, Ankeney ${ }^{14}$ in the United States, Benetti et al ${ }^{15}$ and Buffolo et al ${ }^{16-18}$, Lima et al ${ }^{19}$, and Lobo et al $^{20}$ in Brazil.

Subramanian ${ }^{21}$, Robson et al $^{22}$, Calafiore et al ${ }^{23,24}$, and Karagoz et a ${ }^{25}$ have contributed to the progress of MIDCAB.

With further investigative thinking, we believed in the possibility of performing a MIDCAB using the ambulatory method, and so we performed the surgery on a small series of select patients, who were totally awake and without an endotracheal tube. 
The objective of this article is to present our initial experience with myocardial revascularization performed on an ambulatory basis, with a conscious patient and to note some of the particularities observed.

\section{Methods}

Between January 1994 and May 2001, 272 patients underwent $\mathrm{CABG}$, without the use of CPB. In 24, the surgery was performed without an endotracheal tube and with patients totally conscience. All had a lesion in the left anterior descending artery, and no important chronic pulmonary disease was present. The age ranged from 51-75 years with the predominant sex being males. All patients underwent routine preoperative examinations and psychological preparation before the procedure.

Epidural thoracic administration of the anesthesia was performed with $10 \mathrm{~mL}$ of solution, composed of $8 \mathrm{~mL}$ of bupivacaine, $0.5 \%+2 \mathrm{mg}$ of morphine, injected by needle at the T4 level, with posterior collocation of an $\mathrm{n}^{\circ}$. We used an $18 \mathrm{Gca}$ theter to inject $1 \mathrm{~mL}$ of bupivacaine $0.5 \%$ to block the $2 \mathrm{nd}, 3 \mathrm{rd}$, 4th, and 5th left intercostals spaces (LIS). During surgery, and in the postoperative procedure when necessary, we injected 4 $\mathrm{mL}$ of bupivacaine $0.5 \%$ into the catheter. To obtain 5 metameres of analgesia at T2 to T6, during part of the surgery the patient used an oxygen mask with two $1 /$ minute fluxes.

Monitoring of patients followed the protocol for CABG with CPB. It included continuous electrocardiography, access to the deep vein by puncturing the right jugular vein, arterial pressure by puncturing the radial artery, monitoring of arterial saturation with a pulse oximeter, arterial gasometry before opening the thorax and every 30 minutes after the thoracotomy.

The access used was a thoracotomy at the 4th LIS, with the patient in the dorsal decubitus position, slightly turned to the right at $\mathrm{a} \pm 30^{\circ}$ angle to the surgical table. The length of the incision ranged from 14 and $16 \mathrm{~cm}$. The LITA was dissected through this incision until the subclavian artery was reached, sometimes it being necessary to remove the cartilage of the 4 th rib and occasionally the 5 th. The pericardium was opened longitudinally on the anterior fascia, approximately $2 \mathrm{~cm}$ from the diaphragm close to the pulmonary artery trunk, having its edges well fixed to the edges of the incision. A tourniquet was used close to the LAD zone, where the anastomosis (4/0 Prolene thread, anchored to a small segment of the silicone tube) would have been made, without tightening, with 2 types of stabilizers. After sectioning of the LITA, its extremity was prepared, the coronary was opened, with 1 assistant providing light compression by squeezing the coronary artery, and another assistant blowing $\mathrm{CO}_{2}$, washing the site to keep the area blood-free and for the quick placement of the intracoronary shunt. The tourniquet was only tightened in cases of intense bleeding. The LITA-LAD anastomosis was performed with Prolene 7/ 0 with continuous sutures, and the intracoronary shunt was removed at the end of the anastomosis. During the entire time of surgery, the left lung remained partially collapsed.
Anticoagulation was achieved with heparinization of the patient with $2 \mathrm{mg} / \mathrm{kg}$ of weight, before sectioning of the LITA. The neutralization of the heparin was achieved-with protamine in equal dosages. After the anastomosis, the pericardium was partially sutured, the pleural cavity was drained, and the thoracic wall was closed. Throughout the pneumothorax, we asked the patients to breathe deeply and provoke a cough until the total expansion of the lung was obtained.

After the patients entered the intensive care unit, we immediately initiated respiratory exercises and the oral use of aspirin. The drain was removed within 12 hours. After the removal of the drain, the patient was transferred to a ward.

\section{Results}

The 24 patients endured the surgery well. The mean time of LITA-LAD anastomosis was 9 minutes and the pneumothorax time ranged from 60-190 minutes. During the procedure, no hemodynamic instability or arrhythmias occurred. No important modifications occurred in blood saturation of $\mathrm{PO}_{2}$ and $\mathrm{PCO}_{2}$ (tab. I). One patient needed endotracheal intubation and a sternotomy with installation of CPB after a sudden cardiac arrest at the end of surgery when the thorax had already been closed. After the installation of the $\mathrm{CPB}$, the heart began beating, and the ECG, obtained $15 \mathrm{mi}-$ nutes after the procedure, was normal. This arrest was attributed to the heart coming out of the pericardial sack with a twisting of the vessels at the base. In this case, the pericardium had not been closed. The flux of the LITA was confirmed by a postoperative arteriograph.

Another patient had a thermic lesion of the LITA during its dissection, at the incision angle. The wounded segment was resectioned and a termino-terminal anastomosis was performed, which increased the pneumothorax time to 190 minutes.

No electrocardiographic, echocardiographic, or enzymatic alterations revealed postoperative necroses. No neurologic or infectious complications or clinical pulmonary or radiologic alterations occurred.

All patients, with the exception to the ones that underwent CPB, were stable and released after 24 hours.

\section{Discussion}

During the last decade, percutaneous coronary balloon angioplasty and the implantation of a stent have emerged as the first-choice, offering quick myocardial revascularization and efficient and less aggressive surgery for patients with 1, 2, or 3 compromised vessels, in the absence of disease in the LAD and their indication seems to have expanded, but the use of CABG has been limited.

The literature shows that the benefits of surgery with LITA-coronary anastomosis is superior on a long-term basis ${ }^{26}$. Some surgeons have hesitated to indicate CABG as the first therapeutic procedure in these patients, in view of the mortality, morbidity, and cost associated with surgery 


\begin{tabular}{|c|c|c|c|c|c|c|c|c|c|c|c|c|c|c|c|c|}
\hline \multirow{2}{*}{$\begin{array}{l}\text { Patients } \\
1^{\circ} \text { patient }\end{array}$} & \multirow{2}{*}{$\begin{array}{l}\text { Age } \\
51\end{array}$} & \multirow{2}{*}{$\begin{array}{c}\begin{array}{c}\text { Time of } \\
\text { Pneum. }\end{array} \\
92\end{array}$} & \multicolumn{2}{|c|}{$\frac{\text { Sat } \quad \mathrm{PCO}_{2}}{\text { before }}$} & \multicolumn{2}{|c|}{$\frac{\text { Sat } \quad \mathrm{PCO}_{2}}{30 \mathrm{~min}}$} & \multicolumn{2}{|c|}{$\frac{\text { Sat } \quad \mathrm{PCO}_{2}}{60 \mathrm{~min}}$} & \multicolumn{2}{|c|}{$\frac{\text { Sat } \quad \mathrm{PCO}_{2}}{90 \mathrm{~min}}$} & \multicolumn{2}{|c|}{$\frac{\text { Sat } \mathrm{PCO}_{2}}{120 \mathrm{~min}}$} & \multicolumn{2}{|c|}{$\frac{\text { Sat } \mathrm{PCO}_{2}}{150 \mathrm{~min}}$} & \multicolumn{2}{|c|}{$\frac{\text { Sat, } \mathrm{PCO}_{2}}{190 \mathrm{~min}}$} \\
\hline & & & $99 \%$ & 37 & $98 \%$ & 40 & $97 \%$ & 41 & $97 \%$ & 41 & & & & & & \\
\hline $2^{\circ}$ patient & 75 & 95 & $98 \%$ & 40 & $97 \%$ & 41 & $98 \%$ & 48 & $96 \%$ & 55 & & & & & & \\
\hline $3^{\circ}$ patient & 69 & $85^{\prime}$ & $98 \%$ & 40 & $97 \%$ & 40 & $98 \%$ & 44 & $97 \%$ & 46 & & & & & & \\
\hline $4^{\circ}$ patient & 54 & $90^{\prime}$ & $100 \%$ & 37 & $99 \%$ & 38 & $98 \%$ & 39 & $98 \%$ & 40 & & & & & & \\
\hline $5^{\circ}$ patient & 56 & $80^{\prime}$ & $99 \%$ & 37 & $97 \%$ & 40 & $97 \%$ & 42 & & & & & & & & \\
\hline $6^{\circ}$ patient & 66 & $190^{\prime}$ & $97 \%$ & 39 & $98 \%$ & 41 & $98 \%$ & 41 & $97 \%$ & 44 & $98 \%$ & 45 & $97 \%$ & 48 & $96 \%$ & 48 \\
\hline $7^{\circ}$ patient & 64 & 70 & $98 \%$ & 38 & $98 \%$ & 43 & $98 \%$ & 43 & & & & & & & & \\
\hline $8^{\circ}$ patient & 66 & 72 & $98 \%$ & 39 & $98 \%$ & 42 & $97 \%$ & 42 & & & & & & & & \\
\hline $9^{\circ}$ patient & 73 & $75^{\prime}$ & $97 \%$ & 40 & $96 \%$ & 42 & $96 \%$ & 46 & & & & & & & & \\
\hline $10^{\circ}$ patient & 60 & $81^{\prime}$ & $98 \%$ & 39 & $96 \%$ & 40 & $98 \%$ & 49 & $97 \%$ & 40 & & & & & & \\
\hline $11^{\circ}$ patient & 72 & $95^{\prime}$ & $98 \%$ & 40 & $98 \%$ & 42 & $99 \%$ & 46 & $98 \%$ & 42 & & & & & & \\
\hline $12^{\circ}$ patient & 45 & $84^{\prime}$ & $98 \%$ & 37 & $98 \%$ & 38 & $98 \%$ & 39 & $97 \%$ & 39 & & & & & & \\
\hline $13^{\circ}$ patient & 68 & $100^{\prime}$ & $97 \%$ & 38 & $97 \%$ & 43 & $97 \%$ & 42 & $98 \%$ & 41 & & & & & & \\
\hline $14^{\circ}$ patient & 43 & 68 & $100 \%$ & 40 & $99 \%$ & 39 & $98 \%$ & 44 & & & & & & & & \\
\hline $15^{\circ}$ patient & 41 & $60^{\prime}$ & $100 \%$ & 40 & $99 \%$ & 39 & $98 \%$ & 42 & & & & & & & & \\
\hline $16^{\circ}$ patient & 52 & $68^{\prime}$ & $99 \%$ & 40 & $98 \%$ & 40 & $98 \%$ & 43 & & & & & & & & \\
\hline $17^{\circ}$ patient & 52 & $77^{\prime}$ & $99 \%$ & 39 & $97 \%$ & 43 & $97 \%$ & 44 & & & & & & & & \\
\hline $18^{\circ}$ patient & 71 & $71^{\prime}$ & $100 \%$ & 40 & $96 \%$ & 44 & $97 \%$ & 46 & & & & & & & & \\
\hline $19^{\circ}$ patient & 65 & $68^{\prime}$ & $98 \%$ & 37 & $97 \%$ & 42 & $96 \%$ & 47 & & & & & & & & \\
\hline $20^{\circ}$ patient & 52 & $65^{\prime}$ & $100 \%$ & 39 & $96 \%$ & 43 & $95 \%$ & 45 & & & & & & & & \\
\hline
\end{tabular}

combined with CPB and a median sternotomy. On the other hand, with a relatively high incidence of restenosis after angioplasty and stent implantation ${ }^{27}$, the need arose for surgeons to simplify CABG. These simplified techniques have resulted in less aggression against the patient, lower cost, and more effective results.

The technique of myocardial revascularization without CPB has allowed an even greater advance in MID CAB. Initially, limiting factors for the expansion of MIDCAB were the lack of innovations in instrumentation and the discrepancy between the wish of cardiac surgeons to develop minimally invasive technology and the reception of such technology by the industry. Nowadays, new instruments are available, such as retractors for dissection of the mammary artery, stabilizers, internal shunts, $\mathrm{CO}_{2}$ blowers that keep the area stable and blood-free and the heart perfused, making it easy to perform the anastomosis of the coronary arteries, assuring a high rate of pervious flux. The development by Heigmen et al ${ }^{28}$ of a new stapler for coronary anastomosis reduced surgical time. The introduction of a video-assisted manual technique by Mack et $\mathrm{al}^{29}$ and Benetti et al ${ }^{30}$, and the recent emergence of robotics ${ }^{31}$ have expanded the MIDCAB technique.

Although CABG with the heart beating is already an established reality ${ }^{20}$, its use for intramuscular coronaries and for posterior arteries in large hearts with low ejection fractions is still limited. The lack of determination and preparation of surgical teams are handicaps that should be overcome.

The technique used in our series of patients is different from the mini-thoracotomy technique already established, because of the thoracic epidural block used and the specific psychological preparation of the patients for this procedure. The patient is kept awake the entire time and can talk.

The pneumothorax provoked by the thoracotomy has not caused any problems. The maximum time the thorax was open was 190minutes, and no important alterations occurred in saturation of $\mathrm{O}_{2}$, in arterial pressure or in $\mathrm{PO}_{2}$ and $\mathrm{PCO}_{2}$, through all the surgeries. The incision of the thoracotomy was larger, ranging from 14 to $16 \mathrm{~cm}$, to permit complete dissection of the LITA to the subclavian artery. The time of 190 minutes that the thorax was open in 1 patient was because of the inadequate exposition of the LITA leading to a lesion and posterior reconstruction. This illustrates that the patient can withstand a long pneumothorax without major alterations in ventilation and without postoperative pulmonary complications.

The tourniquet was used only in cases of intense bleeding that could cut and fracture arterial wall plaques, which could be dissected and compromise the anastomosis. The partial collapse due to pneumothorax makes the dissection of the LITA easier and also serves the surgical treatment for pulmonary and mediastinal diseases.

One patient, although having previous psychological preparation, got tired of lying in the same position and moved, causing the surgeon certain discomfort. When the patient breathes deeply, the heart tends to dislocate to below the sternum. This fact becomes less significant when the pericardium is well fixed at the edges, principally on the sternum side, which does not permit dislocation. At the time of anastomosis, the anesthetist asks the patient to cooperate and avoid deep breathing and moving.

Respiratory exercises are done as soon as the patient arrives in the ICU, which is made easier by the type of anesthesia used permitting the exercises to be pain free, avoiding respiratory complications. Before the end of 24 hours after surgery, the patients were already in conditions for hospital discharge. The epidural catheter was removed 72 hours after surgery.

The case of reversion to sternotomy and installation of CPB, because of sudden cardiac arrest, was not believed to be in relation to the proposed operative techniques. 
We believe that we can expand revascularization to more vessels (LAD and diagonal). Possibly in the future, like Benetti et al ${ }^{32}$, we can perform a complete revascularization of the left side of the heart with the patient fully awake, without an endotracheal tube and with normal breathing.

The use of epidural anesthesia and heparinization did not cause complications. We have been using this procedure on a large number of our patients, having operated on more than 560 patients with the epidural and CPB, without any problems. The formation of hematomas in the epidural catheter placement is very rare ${ }^{33}$.

We avoided using drugs that could depress respiration. In this way, the patient maintained normal function keeping $\mathrm{CO}_{2}$ blood levels in acceptable limits. Epidural anesthesia can also reduce the incidence of graft thrombosis by preserving its fibrinolytic system ${ }^{34}$, which can reduce the tendency toward coagulation that exists in patients who undergo $\mathrm{CABG}$ without $\mathrm{CPB}^{35}$ decreasing the incidence of postoperative arrhythmias ${ }^{36}$. Hospital discharge 24 hours after surgery and release of the patient into a home care regime for several days is the ideal, because it avoids the inconveniences of atrial fibrillation that could eventually occur.

Karagoz et al ${ }^{25}$ in October 2000 were pioneers in CABG with fully awake patients; however, they used an ' $\mathrm{H}$ ' radial artery graft, with LITA in situ and the ADA without opening the pleura. In our study, it was different. We opened the pleural cavity without consequences to the patient, eliminating the inconvenience of a possible spasm of the radial artery and blood steal because of dissection from the mam- mary artery to the subclavian and making the anastomosis of the LITA directly to the LAD.

In general, the progress of $\mathrm{CABG}$ began with the elimination of the heart-lung machine and performance of $\mathrm{CABG}$ with the heart beating, followed by the reduction of the size of incision. The last important obstacle for comparison with percutaneous techniques, such as an angioplasty or stent implantation, was to maintain the patient fully awake during the procedure. MIDCAB allows elimination of this obstacle making this procedure efficient and safe.

In relation to the anxiety of the patient at the beginning of this procedure, we offer psychological preparation, which permits, in a pain-free environment, acceptance of the surgical procedure without hostility toward the form. We have had no refusals so far.

Concluding, even though the number of cases is small, the procedure is assuredly safe and viable. The pneumothorax did not cause postoperative morbidity and allowed the creation of a good anastomosis. The surgery could be useful for a large number of patients, and we believe that in the future, with more experience, it can be performed as a routine ambulatory procedure.

\section{Acknowledgements}

To the Drs. José Bruno Souza da Silveira, Hanry Barros Souto, Alessandro Mota Franzini, João Batista de Paula, Gláucio Werneck Mozer and Cynthia Fernandes, for the collaboratrion received.

\section{References}

1. Carrel A. On experimental surgery of the thoracic aorta and the heart. Ann Surg 1910; 52: 83-95.

2. Murray G, Porcheron R, Hilario J, Roschlau W. Anastomosis of a systemic artery to the coronary. Can Med Assoc J 1954; 71: 594.

3. Kahn DR, Mallina RF, Wilson WS, Sloan H. The use of the American and the Russian vascular staplers for coronary artery anastomosis in calves. J Thorac Cardiovasc Surg 1965; 50: 695-705.

4. Kolesov VI. Mamary artery-coronary artery anastomosis as method of treatment for angina pectoris. J Thorac Cardiovasc Surg 1967; 54: 535-44.

5. Olearchyk AS. Vasilie I Kolesov a pioneer or coronary revascularization by internal mamary-coronary artery grafting. J Thorac Cardiovasc Surg 1988; 96: 13-8.

6. Kolesov VI, Kolesov EV. Twenty year results with internal thoracic artery-coronary artery anastomosis. J Thorac Cardiovasc Surg 1991; 101: 306-61.

7. Garret HE, Dennis EW, De Bakey ME. Aorta coronary bypass with saphenous vein graft seven year follow up. JAMA 1973; 223: 792-4.

8. Kirklin JK. Prospects for understanding and eliminating the deleterious effects of cardiopulmonary bypass. Ann Thorac Surg 1991; 51: 529-31.

9. Verrier ED. The vascular endothelium: Friends or Foe? Ann Thorac Surg 1993; 55: 818-9.

10. Gomes WJ, Carvalho ACC, Buffolo E, et al. Vasoplegic syndrome: a new dilema. J Thorac Cardiovasc Surg 1994; 07: 942-3.

11. Blauth CL, Arnold JV, Schulemberg WE, et al. Cerebral microembolism during cardiopulmonary bypass. J Thorac Cardiovasc Surg 1988; 95: 668-76.

12. Parker FB, Masvasti MA, Bove EL. Acute neuropsychological consequences of coronary arter bypass surgery: the role of atherosclerose emboli. Thorac Cardiovasc Surg 1985; 33: 207-9.
13. Trapp WG e Bisarya R. Replacement of coronary artery bypass graft without pump-oxygenator. Ann Thorac Surgery. 1975; 19: 1-9.

14. Ankeney JL. To use or not use the pump oxygenator in coronary bypass operations. Ann Thorac Surg 1975; 19: 108-9.

15. Benetti FJ. Direct coronary with saphenous vein bypass without either cardiopulmonary bypass or cardiac arrest. J Cardiovasc Surg 1985; 26: 217-22.

16. Buffolo E, Andrade JCS, Succi JE, et al. Direct myocardial revascularization without cardiopulmonary bypass. Thorac Cardiovasc Surg 1985; 33: 06-9.

17. Buffolo E, Andrade JCS, Branco JNR, et al. Myocardial revascularization without extracorporeal circulation. Eur J Cardiothoracic Surg 1990; 4: 504-8.

18. Buffolo E, Andrade JCS, Branco JNR, et al. Revascularização do miocárdio sem circulação extra.corpórea: análise dos resultados em 15 anos de experiência. Rev Bras Cir Cardiovasc 1996; 11: 227-31.

19. Lima RC. Avaliação hemodinâmica intra-opertória na cirurgia de revascularização miocárdica sem circulação extra-corpórea. Recife, PE. Tese Prof. Titular Universidade de Pernambuco - Faculdade de Medicina, 1999.

20. Lobo JG, Albuquerque JMAC, Gomes CBG, et al. Revascularização cirúrgica das artérias posteriores do coração sem circulação extra-corpórea. Arq Bras Cardiol 1999; 72: 593-6.

21. Subramanian VA. Less invasive arterial CABG on a beating heart. Ann Thorac Surg 1997; 63(suppl): 568-71.

22. Robison MC, Gross DR, Zeman W, et al. Minimally invasive coronary artery bypass grafting: A new method using an anterior mediastinotomy. J Card Surg 1995; 10: 529-36.

23. Calafiore AM, Di Giammarco G, Teodori G, et al. Left anterior descending coronary artery grafting via left anterior small thoracotomy without cardiopulmonary bypass. Ann Thorac Surg 1996; 61: 1658-68. 
24. Calafiore AM. Technique and results pre and post stabilization era. Symposium Facts and Myths of minimally invasive cardiac surgery. New Orleans, January 24, 1998: p 20.

25. Karagoz HY, Sommez B, Bakkaloglu B, et al. Coronary artery bypass grafting in the conscience patients without endotracheal general anesthesia. Ann Thorac Surg 2000; 70: 91-6.

26. Hueb WA, Belloti G, Oliveira AS, et al. The medicine angioplasty or surgery study (MASS): A prospective randomized trial of medical therapy balloon angioplasty or bypass surgery for single proximal left anterior descendent artery stenoss. J Am Coll Cardiol 1995; 26: 1600-5.

27. Schoming A, Kastrati A, Mudra H, et al. Four-year experience with Palmaz-schatz stenting in coronary angioplasty complicated by dissection with threatened or present vessel closure. Circulation 1994; 90: 2716-23.

28. Heigmen RH, Hinchliffe P, Borst C, et al. A novel one-shot anastomotic stapler prototype for coronary bypass grafting on the beating heart: feasibility in the pig. J Thorac Cardiovasc Surg 1999; 117: 117-25.

29. Mack M, Acuff TE Casimer Ahn H, et al. Video assisted coronary bypass grafting on the beating heart. Ann Thorac Surg 1997; 63(suppl 6): 5100-3.
Myocardial revascularization surgery in conscious patients

30. Benetti FJ, Ballester C, Sani G, et al. Video assisted coronary bypass surgery. J Card Surg 1995; 10: 620-5.

31. Damiano R. Will robotic assistance enable us to perform totally endoscopic CABG? Symposium Facts and Myths of minimally invasive cardiac Surgery. New Orleans, January 24, 1998: p 26.

32. Benetti FJ. Experience with surgery on the beating heart. In: Emery RW, eds. Technique for minimally invasive direct coronary artery bypass (MIDCAB) surgery. Philadelphia: Haley \& Belfus Inc., 1997: 23-6.

33. Vandermeulen EP, Ake HV, Vermylen J. Anticoagulants and spinal-epifural anesthesia. Anesth Analg 1994; 79: 1165-77.

34. Rosenfeld BA, Beattiec C, Christopherson R, et al. The effects of different anesthesia regimens on fibrinolysis and the development of post operative arterial thrombosis. Anesthesiology 1993; 79: 435-43.

35. Mariani MA, Gu YJ, Boonstra PW, Grandjean JG, Van Oeverem W, Ebels T. Procoagulant activity after off.pump coronary operation. Ann Thorac surg 1999; 67 : 1370-5.

36. Goldstein S, Dean D, Kim SJ, Grofsik J, Sillver P, Cody RP. A Survery of spinal and epidural techniques in adult cardiac surgery. J Cardiothorac Vasc Anesth 2001; 15: 158-66. 